\title{
ATYPICAL ANAEROBIC FORMS OF STREPTOCOCCUS PYOGENES ASSOCIATED WITH TETRACYCLINE RESISTANCE
}

\author{
BY \\ E. J. L. LOWBURY AND L. HURST \\ From the Medical Research Council Burns Unit, Birmingham Accident Hospital
}

(RECEIVED FOR PUBLICATION JULy 4, 1955)

The emergence of Streptococcus pyogenes resistant to the tetracycline antibiotics has been noted occasionally during the treatment of streptococcal infection of burns with oral chlortetracycline (Lowbury and Cason, 1954). These resistant strains grew well under aerobic or anaerobic conditions. More recently, however, we have isolated from a number of burned patients streptococci which failed to grow aerobically on ordinary culture media (horse blood agar and nutrient broth), but grew well in anaerobic culture on the same media ; most of these streptococci were resistant to tetracycline compounds. A surprising feature about these organisms is their ability to grow aerobically on a medium containing a higher concentration of agar used to prevent the swarming of Proteus in routine culture from wounds (Hayward and Miles, 1943). These atypical forms, which for convenience we shall refer to as AN forms, are of some practical importance, since they appear to be related to the emergence of tetracycline resistance and would be missed in aerobic culture on ordinary blood agar.

The incidence and some characteristics of AN forms in burns are described in this paper.

\section{Materials and Methods}

Moist swabs from burned patients were examined by methods similar to those reported elsewhere (Jackson, Lowbury, and Topley, 1951). These included inoculation of swabs and of cooked meat broth cultures on " concentrated agar plates," containing $10 \%$ ' defibrinated horse blood and $4 \%$ New Zealand agar* in a Lemco broth base, the medium being poured over a layer of Lemco agar. We shall refer to media containing $4 \%$ agar as " concentrated agar" (with blood, or with serum) ; media containing $1.5 \%$ agar will be called " ordinary blood agar" or " ordinary serum agar."

* The agar used in all the experiments and almost all the routine work was oxoid agar-agar powder (New Zealand). Some culture plates with Davis standard agar (New Zealand) were used at the beginning of the study.
Small haemolytic colonies were examined for morphology in Gram-stained films, and subcultured for grouping on two ordinary blood agar plates (containing $1.5 \%$ New Zealand agar and $10 \%$ horse blood). These plates were incubated, one aerobically and the other anaerobically, at $37^{\circ} \mathrm{C}$. overnight ; the growth was noted and grouping was carried out by Lancefield's method with antisera of groups A, C, D, and G (Wellcome).

Strains of Group A sireptococci were typed for us by Dr. W. H. H. Jebb, of the Oxford Public Health Laboratory.

Fermentation reactions were tested in Hiss's serum water containing $1 \%$ of glucose, laevulose, galactose. lactose, maltose, sucrose, sorbitol. mannitol, salicin. raffinose, and inulin.

Tests for soluble haemolysin were made by the addition of $0.5 \mathrm{ml}$. of six-hour $20 \%$ serum broth cultures tc $0.5 \mathrm{ml}$. of $5 \%$ horse red blood corpuscles in physiological saline and incubating at $37^{\circ} \mathrm{C}$. for 90 minutes.

Anaerobic cultures were set up in a McIntosh and Fildes jar, and incubated overnight at $37^{\circ} \mathrm{C}$.

Antibiotic sensitivity was tested by a ditch plate technique. the agar ditches containing $10, \mathrm{mg} / \mathrm{ml}$. chlortetracycline (aureomycin, Lederle) and of erythromycin ("ilotycin," Lilly), and 10 units $/ \mathrm{ml}$. of penicillin in the agar. Eight strains of the AN form were also tested on ditch plates with oxytetracycline (terramycin, Pfizer) and with tetracycline ("achromycin," Lederle). The minimal inhibitory concentration of these antibiotics against a number of resistant strains was determined by a tube dilution test in nutrient broth.

Other details of technique used in the experimental study of these streptococci are described later with the experiments.

\section{AN Forms of Strep. Pyogenes in Burns}

In October, 1954, cultures on concentrated agar (with blood) from a pedicle graft with purulent exudate showed a heavy growth of minute colonies with zones of faint haemolysis after overnight incubation. The patient, a child who had received extensive burns of the trunk two years previously, 


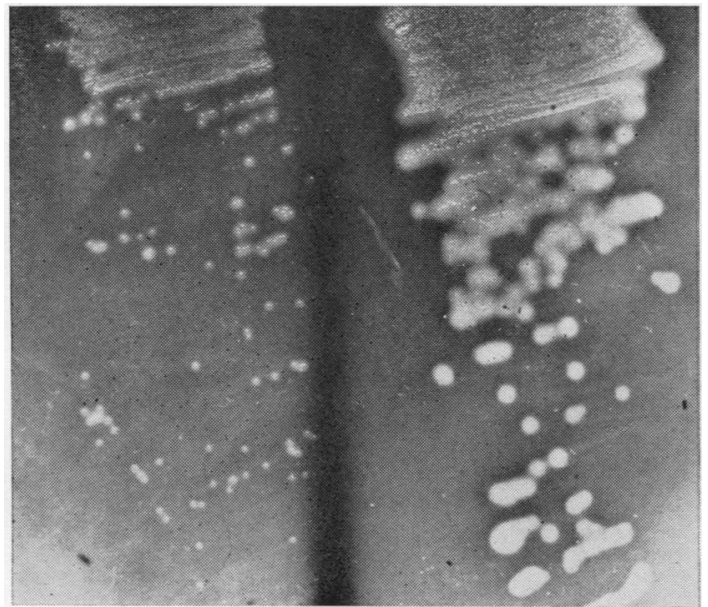

FIG. 1.-Strep. pyogenes growing on concentrate dagar (with blood) Growth on the right side is of an ordinary aerobic strain, that on the left of an AN streptococcus.

had been treated with oral chlortetracycline for streptococcal infection during earlier periods in hospital, the duration of chlortetracycline therapy totalling at least 49 days. Nose and throat swabs taken on admission to hospital in September, 1954, did not yield Strep. pyogenes on ordinary blood agar incubated anaerobically.

Subcultures of the minute colonies grew aerobically and anaerobically on concentrated blood agar, but on ordinary blood agar and in nutrient broth they grew under anaerobic conditions only. The colonies on anaerobic blood agar had the typical appearance of haemolytic streptococci, and microscopic examination showed short chains of Grampositive cocci. They proved to be streptococci of Lancefield's group A, which were sensitive to penicillin and to erythromycin but resistant to all the tetracycline antibiotics.

Similar colonies were soon noticed on cultures from other patients, and it was usually possible to distinguish the AN form from ordinary forms of Strep. pyogenes on concentrated blood agar by its colonial appearance (Fig. 1). Occasionally there was no haemolysis in cultures on this medium.

TABLE I

STREP. PYOGENES ISOLATED FROM BURN SWABS BETWEEN OCTOBER, 1954, AND MARCH, 1955

\begin{tabular}{|c|c|c|c|}
\hline \multirow{2}{*}{$\begin{array}{c}\text { Growth Form } \\
\text { of Strep. pyogenes }\end{array}$} & \multicolumn{2}{|c|}{$\begin{array}{l}\text { Sensitivity Tests with } \\
\text { Chlortetracycline* }\end{array}$} & \multirow[t]{2}{*}{ Total } \\
\hline & Sensitive & Resistant & \\
\hline $\begin{array}{l}\text { Normal aerobic forms .. } \\
\text { AN forms }\end{array}$ & $\begin{array}{r}177 \\
12\end{array}$ & $\begin{array}{r}9 \\
58\end{array}$ & $\begin{array}{r}186 \\
70\end{array}$ \\
\hline Total .. & 189 & 67 & 256 \\
\hline
\end{tabular}

* Results of ditch plate sensitivity tests.
The Incidence of AN Forms in Burns.-Table I gives the numbers of swabs from which typical and AN forms of group A haemolytic streptococci were isolated between October 12, 1954, and March 3, 1955. This shows that no fewer than 70 out of the 256 strains isolated in that period had the colonial appearance and the anaerobic growth requirements of the $\mathrm{AN}$ form; the majority of these $(58 / 70)$ were resistant to chlortetracycline. Of the 186 normal aerobic forms, 177 were sensitive to chlortetracycline. The AN strains, which were also tested with tetracycline and oxytetracycline, showed the same sensitivity to these antibiotics as towards chlortetracycline. Tube dilution sensitivity tests showed that the minimal inhibitory concentration of the three tetracycline antibiotics against five of the resistant strains was $50-100$ $\mu \mathrm{g} . / \mathrm{ml}$.

Tetracycline Therapy and the Presence of AN Forms.-Oral tetracycline or oxytetracycline was administered as a specific treatment for burns on which Strep. pyogenes had been found. Treatment was usually started before the antibiotic sensitivity was known. Most of these streptococci were aerobic and tetracycline-sensitive, in which case they were regularly eliminated from burns after three to six days of treatment.

As would be expected from their normal insensitivity to tetracyclines, AN forms of streptococci present at the beginning of treatment with tetracyclines were found to persist in burns throughout the course of treatment. In other cases they were found to appear during or after such a course. Of the 19 patients in whose burns AN forms were found, eight showed the organisms during or shortly after a course of oxytetracycline or tetracycline. In two cases both sensitive and resistant AN forms were found, one of them yielding the sensitive organisms before, and resistant organisms after, a course of tetracycline therapy.

The association of the presence of AN forms and tetracycline therapy in 19 patients is shown in Table II.

Erythromycin was always effective in eliminating $\mathrm{AN}$ forms from burns; a higher dosage (2 g., in divided doses, daily. for adults) than that previously found effective (Lowbury and Cason, 1954) was used in thesê patients.

Pathogenic Role of AN Forms.-Out of 23 skin grafting operations in the presence of AN streptococci, 20 showed less than $80 \%$ "take" (Table III). This is similar to the proportion of such failures in the presence of aerobic Strep. pyogenes, 
TABLE II

TETRACYCLINE THERAPY AND THE INCIDENCE OF AN FORMS IN BURNS

\begin{tabular}{|c|c|c|c|c|c|c|c|c|c|c|c|c|c|}
\hline \multirow{5}{*}{ Patient } & \multirow{5}{*}{$\begin{array}{l}\text { Tetracycline } \\
\text { Therapy before } \\
\text { AN Forms } \\
\text { Appeared }\end{array}$} & \multicolumn{12}{|c|}{ Streptococcus pyogenes Isolated from Burns* } \\
\hline & & \multicolumn{6}{|c|}{ Aerobic Form } & \multicolumn{6}{|c|}{ AN Form } \\
\hline & & \multicolumn{3}{|c|}{ Tetracycline Sensitive } & \multicolumn{3}{|c|}{ Tetracycline Resistant } & \multicolumn{3}{|c|}{ Tetracycline Sensitive } & \multicolumn{3}{|c|}{ Tetracycline Resistant } \\
\hline & & \multirow[b]{2}{*}{ Date } & \multicolumn{2}{|c|}{ Type } & \multirow[b]{2}{*}{ Date } & \multicolumn{2}{|c|}{ Type } & \multirow[b]{2}{*}{ Date } & \multicolumn{2}{|c|}{ Type } & \multirow[b]{2}{*}{ Date } & \multicolumn{2}{|c|}{ Type } \\
\hline & & & $\begin{array}{c}\text { Agglu- } \\
\text { tination }\end{array}$ & $\begin{array}{c}\text { Precipi- } \\
\text { tation }\end{array}$ & & $\begin{array}{c}\text { Agglu- } \\
\text { tination }\end{array}$ & $\begin{array}{c}\text { Precipi- } \\
\text { tation }\end{array}$ & & $\begin{array}{c}\text { Agglu- } \\
\text { tination }\end{array}$ & $\begin{array}{c}\text { Precipi- } \\
\text { tation }\end{array}$ & & $\begin{array}{c}\text { Agglu- } \\
\text { tination }\end{array}$ & $\begin{array}{c}\text { Precipi- } \\
\text { tation }\end{array}$ \\
\hline 873 & 1952 and $1953 \ldots$ & $\underset{1953}{1952 \text { and }}$ & - & - & None & - & - & None & - & - & 12.10 .54 & 52744 & 0 \\
\hline $\begin{array}{r}299 \\
281\end{array}$ & None $\quad$. & $\begin{array}{c}\text { None } \\
21.10 .54\end{array}$ & 52744 & $\overline{0}$ & $\begin{array}{c}18.10 .54 \\
\text { None }\end{array}$ & - & 二 & $\ddot{.}$ & 二 & 二 & $\begin{array}{l}18.10 .54 \\
27.10 .54\end{array}$ & 4 & 4 \\
\hline 938 & $\begin{array}{l}5 \text { to } 10.11 .54 \text { (be- } \\
\text { fore resistant } \\
\text { AN forms ap- }\end{array}$ & & & 0 & & & & 201054 & & & & & \\
\hline 434 & $\begin{array}{cc}\text { peared) } \\
\text { None }\end{array} \quad \ldots$ & $\begin{array}{l}18.10 .54 \\
17.10 .54\end{array}$ & $\begin{array}{l}4 \\
4\end{array}$ & $\begin{array}{l}4 \\
4\end{array}$ & $\ddot{,}$ & - & 二 & $\begin{array}{c}29.10 .54 \\
\text { None }\end{array}$ & 4 & $\stackrel{4}{-}$ & $\begin{array}{l}11.11 .54 \\
16.11 .54\end{array}$ & 52744 & $\underline{0}$ \\
\hline 618 & 5 to 17.10 .54 & None & - & - & ,.. & - & - & & $=$ & - & 20.10 .54 & - & - \\
\hline 349 & None $\ldots$ & 20.10 .54 & 4 & 4 &.. & - & - & 23.10 .54 & $\begin{array}{lll}527 & 44\end{array}$ & 0 & -1 & - & - \\
\hline 689 & 14 to 23.10 .54 & 12.10 .54 & 825 & 0 & ,., & - & - & None & -1 & - & 23.10 .54 & - & - \\
\hline 361 & 26.11 to 4.12 .54 & 22.11 .54 & 52744 & 0 & , & - & - & , & - & - & 12.12 .54 & - & - \\
\hline $\begin{array}{l}743 \\
995\end{array}$ & $\begin{array}{ll}\text { None } \\
5 \text { to } 20.1 .55\end{array}$ & $\begin{array}{c}\text { None } \\
29.12 .54\end{array}$ & 二 & 三 & $10 \ddot{1.55}$ & $5 \overline{44}$ & $\overline{0}$ & ,, & 二 & 二 & $\begin{array}{l}19.12 .54 \\
: 0.1 .55\end{array}$ & $5 \overline{27} 44$ & $\overline{0}$ \\
\hline 450 & 14 to 28.1 .55 & 12.1 .55 & $\begin{array}{lll}5 & 12 & 44\end{array}$ & 12 & 9.2 .55 & $5: 12: 44$ & 0 & 5.2 .55 & - & - & $\left\{\begin{array}{l}27.1 .55 \\
3.25\end{array}\right.$ & 51244 & $12\}$ \\
\hline $979 a$ & None $\ldots$ & 5.2 .55 & 52744 & 0 & None & - & - & None & - & - & 5.2 .55 & $527^{2}$ & 0 \\
\hline 555 &, & 22.2 .55 & & - & & - & - & , & - & - & 18.2 .55 & 52744 & 0 \\
\hline 961 & 11 to 24255 & 5.2 .55 & 313 & 0 & 12.2 .55 & - & - & ", & - & - & 13.2 .55 & $=7$ & 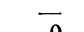 \\
\hline $\begin{array}{l}330 \\
761\end{array}$ & $\begin{array}{l}11 \text { to } 24.2 .55 \\
18 \text { to } 28.2 .55\end{array}$ & 8.2 .55 & 544 & $\begin{array}{r}0 \\
28\end{array}$ & None & $\overline{-}$ & E &, & E & $\overline{-}$ & $\begin{array}{r}22.2 .55 \\
1.3 .55\end{array}$ & $\begin{array}{l}52744 \\
52744\end{array}$ & $\begin{array}{l}0 \\
0\end{array}$ \\
\hline $979 b$ & None & $\begin{array}{l}18.2 .53 \\
\text { None }\end{array}$ & 28 & 28 & ,.. & 二 & 二 & ," & 二 & - & 28.2 .55 & & - \\
\hline 457 & , $\quad$. & 27.2 .55 & - & - & ," & - & - & , & - & - & 28.2 .55 & 52744 & 0 \\
\hline
\end{tabular}

* Dates refer to the first isolation of the form of streptococcus indicated at the head of the column.

and is in marked contrast with the results of skin grafting burns free from streptococci (Lowbury and Cason, 1954).

In addition to its association with failure of skin grafts, the presence of $\mathrm{AN}$ forms in burns and on pedicle grafts was often associated with suppuration and other local signs of infection.

Serological Types of the AN Forms.-The AN forms from 11 of the patients were typed (Table II). From 10 of these the streptococci showed the agglutination pattern $5 / 27 / 44$ or a related pattern $(5 / 27,5 / 44,5 / 44 / 12)$. Two other agglutination types were found, 2 and 4 . The AN strain of type 2 was isolated from a patient (450)

TABLE III

AN FORMS OF STREP. PYOGENES IN BURNS AND SKIN GRAFT RESULTS

\begin{tabular}{l|c|c|c}
\hline \multicolumn{1}{c|}{$\begin{array}{c}\text { Strep. pyogenes } \\
\text { in Burns }\end{array}$} & $\begin{array}{c}80 \% \\
\text { or More } \\
\text { Take } \\
\text { (Successful } \\
\text { Graft) }\end{array}$ & $\begin{array}{c}\text { Less } \\
\text { than 80\% } \\
\text { Take } \\
\text { (Failed } \\
\text { Graft) }\end{array}$ & Total \\
\hline $\begin{array}{c}\text { AN forms present } \\
\begin{array}{c}\text { Aerobic forms present* } \\
\text { Burns cleared of strepto- } \\
\text { cocci by antibiotic } \\
\text { therapy* }\end{array}\end{array}$ & 3 & $\begin{array}{c}20(87 \%) \\
16(88 \%)\end{array}$ & 18 \\
\hline
\end{tabular}

* These data from a previous investigation (Lowbury and Cason, 1954) are quoted here for comparison. who yielded AN streptococci of agglutination pattern $5 / 44 / 12$ on another burn five days before and aerobic tetracycline-resistant organisms of the same type again one week later. Two patients had AN streptococci of agglutination and precipitation type 4 on their burns. Only one other patient yielded AN streptococci which gave a precipitation reaction (type 12); aerobic tetracyclinesensitive streptococci from the same patient at an earlier date were found to have the same agglutination and precipitation type. A number of aerobic tetracycline-sensitive streptococci of types 4 and $5 / 27 / 44$ were isolated from other patients in the ward at the same time as those who yielded AN streptococci of these types.

From five patients typing results were obtained on aerobic sensitive strains of Strep. pyogenes which were present on burns before the appearance of AN forms. Two of these patients (450 and 330 ) had type 5/27/44 tetracycline-sensitive aerobic strains initially, and this or a related agglutination pattern was found in the AN tetracycline-resistant form which appeared later (in each case after a course of a tetracycline antibiotic). In the three other patients $(938,349$ and 761) AN strains of type $5 / 27 / 44$ appeared in the place of unrelated aerobic strains (two of type 4 and one of type 28); two of these patients had 
been treated with a tetracycline antibiotic before the AN form appeared.

In one case (995) during tetracycline therapy an aerobic-resistant streptococcus of type 5/44 was isolated on the same day as an AN form of type $5 / 27 / 44$. In another case (450) the presence of an AN-resistant form was followed by the isolation of an aerobic-resistant streptococcus of the same type 12 days after the end of tetracycline therapy; a tetracycline-sensitive AN strain was isolated from the same patient.

Haemolysis and Fermentation Reactions of AN Forms.-Soluble haemolysin was produced by all of the six strains tested. Three strains which were tested showed a range of fermentation reactions similar to that obtained from aerobic strains. Acid was produced from glucose, laevulose, galactose, lactose, maltose, and sucrose, and there was no fermentation of mannitol, sorbitol, raffinose, and inulin. The reactions with salicin were variable.

No difference could be detected in the morphology of Gram-stained films of AN forms and of aerobic strains of Strep. pyogenes from burns.

\section{Experimental Study of AN Forms}

Change to Aerobic Mode of Growth.-Cultures of AN forms on Dorset egg medium and on blood agar allowed to stand for 48 hours or longer at room temperature were often found to grow aerobically on subculture to ordinary blood agar or nutrient broth. Further subcultures remained aerobic. The change to an aerobic mode of growth in these organisms was not accompanied by any loss of resistance to the tetracycline antibiotics.

Daily anaerobic subculture in nutrient broth of AN forms from three patients was not accompanied by any change to aerobiosis until 20 or more transfers had been made. At this stage a subculture from broth, which gave a confluent growth on anaerobic blood agar culture, yielded a few isolated colonies on blood agar plates incubated aerobically, and these could be further subcultured under aerobic conditions.

Strains which had adopted the aerobic mode of growth sometimes showed small weakly haemolytic colonies similar to those of the AN form; but usually they were strongly haemolytic and indistinguishable from a normal aerobic strain.

Emergence of Tetracycline Resistance in vitro.During an attempt to induce resistance to tetracycline and oxytetracycline, a strain of sensitive aerobic Strep. pyogenes was found to have become resistant to these antibiotics (but still aerobic) after standing for several days on Dorset egg medium.
This organism was isolated from the burn of a patient (979a) who yielded a resistant AN streptococcus of the same serological type on the same day.

Effect of Tetracycline on Retention of AN Characteristics.-Three tetracycline-resistant AN strains of Strep. pyogenes were each subcultured to two blood agar plates, one of which contained oxytetracycline $(12 \mu \mathrm{g} . / \mathrm{ml}$.). After incubation (anaerobic), the plates were allowed to stand for three days and subcultured in duplicate on ordinary blood agar plates. These subcultures were incubated at $37^{\circ} \mathrm{C}$, , one aerobically and the other anaerobically.

All three strains were found to have changed to normal aerobic growth after standing on blood agar without the antibiotic. Subcultured from oxytetracycline blood agar, however, the three streptococci retained their AN characteristics. A second oxytetracycline plate inoculated with these organisms was allowed to stand for three days and again showed AN forms on subculture. In further subcultures on oxytetracycline plates, however, aerobic colonies started to emerge.

Tests on Filtrates of AN Forms.-No growth, aerobic or anaerobic, was obtained from Seitz filtrates of anaerobic broth cultures of one AN strain of Strep. pyogenes.

The Phenomenon of Conditional Aerobiosis.Fig. 2 illustrates the peculiar growth characteristics of the AN forms of Strep. pyogenes. Two plates are shown. Each is divided in two halves, the left half containing concentrated agar (with blood), while the right half contains ordinary blood agar. Strains (1) and (3) (aerobic streptococci) grow equally well on the ordinary and on the concentrated agar medium under aerobic or anaerobic conditions. $\mathrm{Cl}$. welchii grows well on either medium anaerobically, but on neither medium aerobically. Strain 2, the AN form, grows well anaerobically on either medium; aerobically it grows only on the concentrated agar $\mathcal{N}$ medium. This phenomenon is found also when $N$ concentrated agar is enriched with serum instead of blood.

The atypical streptococcus cannot be described as "anaerobic" except in relation to particular media. "Conditional aerobiosis" describes the $\stackrel{\oplus}{\rightarrow}$ phenomenon more accurately.

Possible Mechanism of Conditional Aerobiosis. -It has long been known that the growth of some $\stackrel{\Phi}{\Phi}$ haemolytic streptococci is favoured by anaerobic $\stackrel{\mathbb{Q}}{\Omega}$ conditions (e.g., Rosenow, 1914; Oliver and $\frac{0}{2}$ Perkins, 1919). It is also well known that primary 
isolation of Strep. pyogenes from sites of infection is more frequent on anaerobic than on aerobic culture (Ministry of Health Mon. Bull., 1942 ; Williams and Miles, 1945).

The demonstration by M'Leod and Gordon (1922) that haemolytic streptococci often form peroxide on aerobic culture provides a possible explanation of their preference for anaerobic conditions. Todd (1930) showed that streptococci of the matt virulent type produce more hydrogen peroxide on aerobic culture and are also more sensitive to it than glossy avirulent variants; self sterilization, especially of the matt colonies, resulted from the accumulation of hydrogen peroxide in cultures, which did not, however, occur until the end of the logarithmic phase of growth.

It seems to us that $\mathrm{AN}$ forms may fail to grow aerobically either because exceptional quantities of hydrogen peroxide are produced at an early stage of growth, or because these organisms are exceptionally sensitive to hydrogen peroxide. Their ability to grow on concentrated blood or serum agar might, on this hypothesis, be due to the production of hydrogen peroxide being suppressed on these media. We therefore tested growth of aerobic streptococci on ordinary serum agar and on concentrated agar (with serum) for hydrogen peroxide by the potato-benzidine test (see Todd, 1930). Growth of AN streptococci on ordinary serum agar (anaerobic) and on concentrated agar (with serum) (aerobic) was also tested for production of hydrogen peroxide. Several tetracycline-resistant strains derived from AN forms were included among the aerobic streptococci.

Table IV shows that no hydrogen peroxide could be detected in any streptococcus growing aerobically on concentrated agar (with serum) or anaerobically on ordinary serum agar; aerobic cultures on ordinary serum agar, however, yielded abundant hydrogen peroxide (except in the case of three out of seven tetracycline-resistant organisms derived from AN forms). The AN forms were therefore found to grow under conditions which

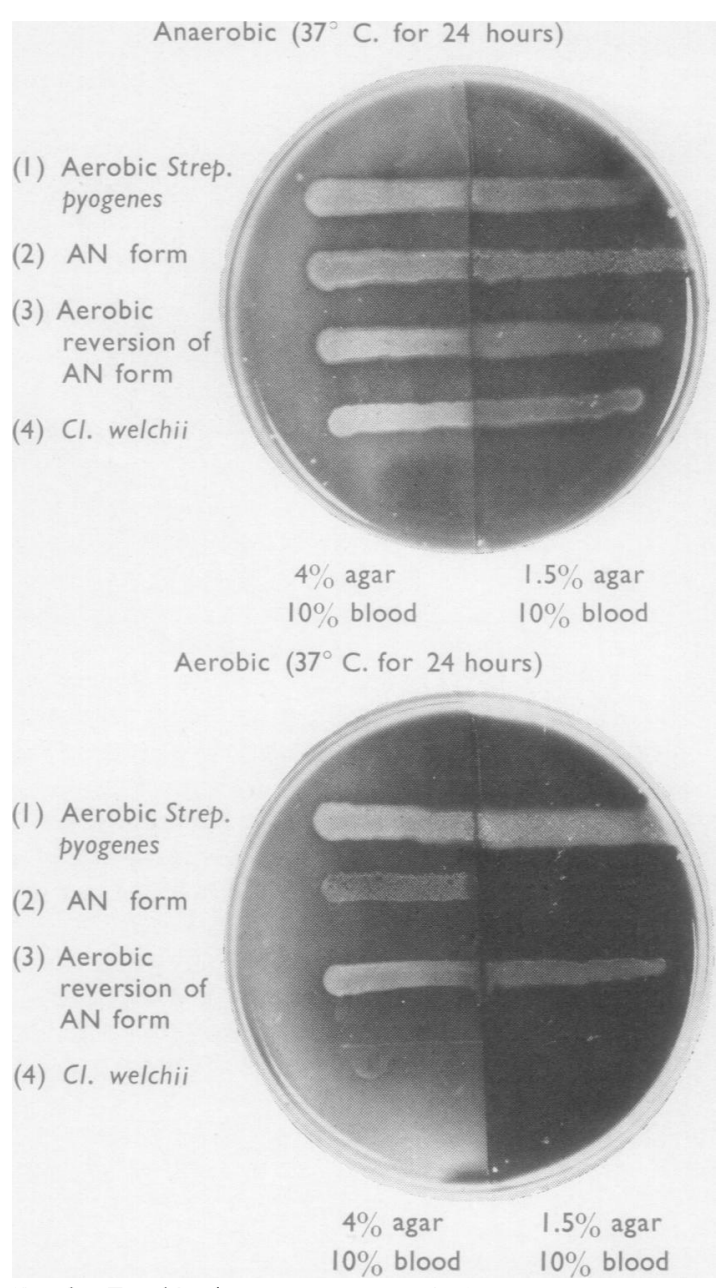

Fig. 2.-Two blood agar plates streaked with the different cultures under discussion, the upper plate incubated anaerobically, the lower aerobically.

were unfavourable to the production of hydrogen peroxide, and did not grow under conditions which favoured its production.

We could find no difference in the sensitivity of aerobic streptococci and of AN forms to the

TABLE IV

HYDROGEN PEROXIDE PRODUCTION ON SERUM AGAR MEDIA

\begin{tabular}{|c|c|c|c|c|c|c|c|}
\hline \multirow{3}{*}{ Organism } & \multirow{3}{*}{$\begin{array}{l}\text { No. of } \\
\text { Strains }\end{array}$} & \multicolumn{4}{|c|}{$1.5 \%$ Agar in Medium } & \multirow{2}{*}{\multicolumn{2}{|c|}{$\frac{4 \% \text { Agar in Medium }}{\text { Aerobic Culture }}$}} \\
\hline & & \multicolumn{2}{|c|}{ Aerobic Culture } & \multicolumn{2}{|c|}{ Anaerobic Culture } & & \\
\hline & & Growth & $\mathrm{H}_{2} \mathrm{O}_{2}$ & Growth & $\mathrm{H}_{2} \mathrm{O}_{2}$ & Growth & $\mathrm{H}_{2} \mathrm{O}_{2}$ \\
\hline 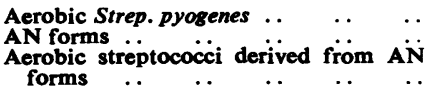 & $\begin{array}{l}6 \\
4 \\
7\end{array}$ & $\begin{array}{l}+++ \\
+0 \\
++\end{array}$ & $\begin{array}{l}+\frac{+}{-} \\
+\underset{0(3)}{+(4)}\end{array}$ & $\begin{array}{l}+++ \\
+++ \\
+++\end{array}$ & $\begin{array}{l}\mathbf{0} \\
\mathbf{0} \\
\mathbf{0}\end{array}$ & $\begin{array}{l}+++ \\
++ \\
++ \\
++\end{array}$ & $\begin{array}{l}\mathbf{0} \\
\mathbf{0} \\
\mathbf{0}\end{array}$ \\
\hline
\end{tabular}


bactericidal action of hydrogen peroxide. Todd (1930), however, reports that the difference in sensitivity to hydrogen peroxide of matt and of glossy strains refers to the bacteriostatic tests only. Such tests on the AN form were impracticable because of the instability of hydrogen peroxide under the anaerobic conditions which would be required. A bactericidal mechanism is, however, suggested by the fact that plates inoculated with AN streptococci, showing no growth after aerobic incubation, showed no growth after further incubation in an anaerobic jar. Further aerobic incubation of such plates also failed to show growth of streptococci.

\section{Discussion}

The appearance of Strep. pyogenes which fails to grow aerobically on ordinary blood agar is a finding which may be expected to become more common if tetracycline-resistant strains are allowed to accumulate in the population. It is important that these organisms should not be missed, as they appear to be of clinical importance and cannot be eliminated by tetracycline. All the strains we have examined are sensitive to penicillin and to erythromycin. Systemic penicillin has been found ineffective for the treatment of established infection of burns with Strep. pyogenes (Jackson et al., 1951), presumably because of the presence of penicillinase-producing organisms (especially Staph. aureus) in the same burn. Erythromycin is highly effective in eliminating AN streptococci from the burn surface, but in view of the importance of preventing acquired resistance in staphylococci it is, perhaps, desirable to try repeated applications of concentrated penicillin cream $(10,000$ units per $\mathrm{g}$.) before prescribing erythromycin for this purpose.

The capacity of concentrated agar to allow aerobic growth of these AN forms is an unexpected virtue in a medium which has already proved its value in preventing the swarming of Proteus. The mechanism of this conditional aerobiosis is uncertain, but our experiments show an association between conditions that allow the growth of these organisms and conditions that are unfavourable to the production of hydrogen peroxide by aerobic streptococci. It is possible that AN forms produce more peroxide or are more sensitive to it than aerobic streptococci. If this is the mechanism, it is perhaps surprising that AN forms fail to grow aerobically on ordinary blood agar, as the catalase in the blood prevents accumulation of detectable hydrogen peroxide on the surface culture of typical Strep. pyogenes.
Catalase in blood agar, however, cannot be assumed to prevent the accumulation of inhibitory concentrations of hydrogen peroxide inside the bacterial cells.

The association of AN streptococci with tetracycline resistance suggests that they emerged as a consequence of tetracycline therapy, either by selection of mutants or by adaptation. Three unrelated serological types of Strep. pyogenes have appeared with AN characteristics in six months, a fact which suggests that this transformation is not rare, and proves that the outbreak of infection with AN forms did not arise by cross-infection from a single mutant. It is of interest that the AN strains included one of precipitin type 12, which is known to have a special association with acute nephritis, and most of the other AN strains were agglutinated by antisera to types 5,27 , and 44 , which are related to type 12 (Dingle, Rammelkamp, and Wannamaker, 1953 ; Wilmers, Cunliffe, and Williams, 1954). The successive isolation first of sensitive aerobic and then of resistant AN streptococci of the same type from the same patient suggests that such changes were occurring in burns, particularly when the AN form appeared after tetracycline treatment. Cross infection with AN forms was, however, common, since more than half of the patients from whom they were isolated had not received tetracyclines.

In its association with acquired antibiotic resistance and its small colony size, the AN form shows some resemblance to the appearance of " $G$ " colonies of staphylococci and other organisms (e.g., Hadley, Delves, and Klimek, 1931 ; Wise and Spink, 1954). Another point of resemblance is the reversion to the normal kind of growth (aerobic) on storage or repeated subculture away from the antibiotic. It seems probable that the reversion to aerobiosis is, in fact, a final stage in the establishment of resistance to tetracycline. The AN form would, on this hypothesis, be an intermediate stage in the development of tetracycline resistance in which there is a temporary narrowing of the of adaptability of the organism to environmental N changes.

Tests in vitro did not show the emergence of AN forms from stable Strep. pyogenes exposed to tetracyclines ; they did, however, suggest that the presence of tetracyclines might delay the establishment of full aerobic growth in AN streptococci.

\section{Summary}

Haemolytic streptococci of group A (AN) $\stackrel{\mathbb{Q}}{\varrho}$ isolated from burns of 19 patients during the course of six months had the following character- 
istics : (1) anaerobic but no aerobic growth in broth and on serum or horse blood agar (1.5\% agar); (2) both aerobic and anaerobic growth on serum or blood agar containing $4 \%$ agar (concentrated agar media); (3) resistance to the tetracycline antibiotics in most strains ; (4) sensitivity to penicillin and erythromycin; and (5) reversion to aerobiosis without loss of tetracycline-resistance on storage.

Eight of the patients had received tetracycline shortly before these AN forms appeared, and another had received prolonged courses of tetracycline therapy in the previous two years. Three different agglutination types were represented, but most strains were of type $5 / 27 / 44$ or a related pattern. Skin grafts usually failed in the presence of these organisms.

Hydrogen peroxide was produced in surface cultures of aerobic streptococci on $1.5 \%$ but not on $4 \%$ agar. The bearing of this observation on "conditional aerobiosis" of the AN form is discussed.

We are grateful to Dr. W. H. H. Jebb, of the Oxford Public Health Laboratory, for typing our streptococci ; we also wish to thank Mr. H. Lilly, A.I.M.L.T., and Miss Georgina Hogg for assistance, and Mr. C. Richardson, A.I.B.P., A.R.P.S., for the photographs.

\section{REFERENCES}

Dingle, J. H., Rammelkamp, C. H., and Wannamaker, L. W. (1953). Lancet, 1, 736.

Hadley, P., Delves, E., and Klimek, J. (1931). J. infect. Dis., 48, 1. Hayward, N. J., and Miles, A. A. (1943). Lancet, 2, 116.

Jackson, D. M., Lowbury. E. J. L., and Topley, E. (1951). Ibid., 2, 705 .

Lcwbury, E. J. L., and Cason, J. S. (1954). Brit. med. J., $2,914$.

M'Leod, J. W., and Gordon, J. (1922). J. Path. Bact., 25, 139. Ministry of Health (1942). Monthly Bull. Emergency Publ. Hlth Lab. Service, 1, February, p. 11.

Oliver, W. W., and Perkins, O. C. (1919). J. infect. Dis., 24, 22.

Rosenow, E. C. (1914). Ibid., 14, 61.

Todd, E. W. (1930). Brit. J. exp. Path., 11, 368.

Williams, R. E. O., and Miles, A. A. (1945). J. Path. Bact., 57, 27.

Wilmers, M. J., Cunliffe, A. C., and Williams, R. E. O. (1954) Lancet, 2, i7.

Wise, R. I., and Spink, W. W. (1954). J. clin. Invest., 33, 1611. 